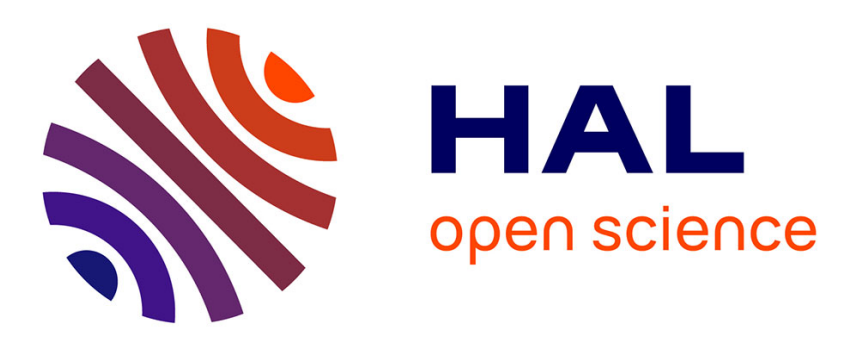

\title{
Does the Great Recession imply the end of the Great Moderation? International evidence
}

\author{
Amélie Charles, Olivier Darné, Laurent Ferrara
}

\section{To cite this version:}

Amélie Charles, Olivier Darné, Laurent Ferrara. Does the Great Recession imply the end of the Great Moderation? International evidence. Economic Inquiry, 2018, 56 (2), pp.745-760. 10.1111/ecin.12551. hal-01757081

\section{HAL Id: hal-01757081 \\ https://hal-audencia.archives-ouvertes.fr/hal-01757081}

Submitted on 3 Apr 2018

HAL is a multi-disciplinary open access archive for the deposit and dissemination of scientific research documents, whether they are published or not. The documents may come from teaching and research institutions in France or abroad, or from public or private research centers.
L'archive ouverte pluridisciplinaire HAL, est destinée au dépôt et à la diffusion de documents scientifiques de niveau recherche, publiés ou non, émanant des établissements d'enseignement et de recherche français ou étrangers, des laboratoires publics ou privés. 


\title{
Does the Great Recession imply the end of the
}

\section{Great Moderation? International evidence}

\author{
Amélie CHARLES* \\ Audencia Business School \\ Olivier DARNÉ ${ }^{\dagger}$ \\ LEMNA, University of Nantes
}

Laurent FERRARA

Banque de France and

EconomiX, University Paris Ouest La Défense

*Audencia Business Nantes, School of Management, 8 route de la Jonelière, 44312 Nantes Cedex 3. Email: acharles@audencia.com.

†Corresponding author: LEMNA, University of Nantes, IEMN-IAE, Chemin de la Censive du Tertre, BP 52231, 44322 Nantes, France. Email: olivier.darne@univ-nantes.fr.

†EconomiX, University Paris Ouest La Défense, and Banque de France, International Macroeconomics Division. Email: laurent.ferrara@banque-france.fr. 


\begin{abstract}
In this paper we examine whether or not the Great Recession had a temporary or permanent effect on output growth volatility after years of low macroeconomic volatility since the early eighties. Based on break detection methods applied to a set of advanced countries, our empirical results do not give evidence to the end of the Great Moderation period but rather that the Great Recession is characterized by a dramatic short-lived effect on the output growth but not on its volatility. We show that neglecting the breaks both in mean and in variance can have large effects on output volatility modeling based on GARCH specifications.
\end{abstract}

Keywords: Great Recession; Great Moderation; breaks; volatility.

JEL Classification: E32; C22; O40. 


\section{Introduction}

Over the past 30 years, macroeconomic volatility has declined substantially in most developed countries, characterized in the literature as "The Great Moderation" period. This decline in output volatility captured the attention of macroeconomists, especially because it occurred in numerous developed countries, although the timing and details differ from one country to the other. Among the huge empirical literature on this topic, Kim and Nelson (1999), McConnell and Perez-Quiros (2000), Blanchard and Simon (2001), Stock and Watson (2003), Ahmed et al. (2004) and Bernanke (2004), among others, document a structural change in the volatility of US GDP growth, finding a rather dramatic reduction in GDP volatility since the early eighties. As regards other advanced countries, Mills and Wang (2003), Summers (2005), Stock and Watson (2005), Fang et al. (2008), and Smith and Summers (2010) discover a structural break in the volatility of the output growth rate for the $\mathrm{G} 7$ countries, although the break occurred at different times. At a more global level, Cecchetti et al. (2006) examine shifts in the volatility of output growth in 25 advanced and emerging countries and find at least one break in all but nine countries and at most two breaks in six of the 25 countries.

Among the potential factors of this Great Moderation period, the literature put forward (i) 'good practices', i.e.: improved inventory management (e.g., McConnell and Perez-Quiros, 2000); (ii) 'good policies', i.e.: good monetary policy (e.g., Clarida et al., 2000; Bernanke, 2004; Boivin and Giannoni, 2006; Gali and Gambetti, 2009); and (iii) 'good luck', i.e.: a decline in the volatility of exogenous shocks (e.g., Stock and Watson, 2003, 2005; Ahmed et al., 2004).

However, after years of moderate volatility in output, the recent "Great Recession" throughout the years 2008 and 2009, that affected most of the advanced countries, as 
well as some emerging countries, in the wake of the global financial crisis, has strongly surprised macroeconomists by its large amplitude ${ }^{1}$ Among the various explanations of this unexpected severity, Stock and Watson (2012) argue that the macroeconomic shocks were much larger than previously experienced, at least for the US, especially the shocks associated with financial disruptions and heightened uncertainty. This large shocks hypothesis is also supported in a sense by Ferrara et al. (2015) who show that the Great Moderation does not come with an increase of the non-linear dynamics within macroeconomic variables, suggesting thus that a linear behaviour with shocks may be more appropriate to describe this specific period of time. Some authors also put forward the major accelerating role of international trade (see Baldwin, 2009), that contributed to the deepness and the worldwide synchronization of this phenomenon.$^{2}$ A policy-relevant issue is to know whether this Great Recession implies the definitive end of the Great Moderation period or if it can be considered as a short-lived phenomenon with no medium-to-long term impact on the macroeconomic volatility. Indeed if we assume that we entered a new era of high macroeconomic volatility, in conjunction with a new era of lower potential growth (which seems to be case for many advanced countries, although this is currently a highly debated issue, see, e.g, Reifschneider et al., 2013, as regards the US economy), thus this would lead to more frequent recessions, as defined in the NBER sense, i.e. a prolonged and substantial decline in the aggregate level of output. Some studies argue in favor of a shift to a new regime of output growth volatility (e.g., Bean, 2010; Cannarella et al., 2010; Taylor, 2011; Ng and Wright, 2013), other evidence suggests that the Great Moderation might not be over (Chen, 2011; Stock and Watson, 2012; Gadea et al., 2014, 2015).

\footnotetext{
${ }^{1}$ Reinhart and Rogoff (2009) call the period of the Great Recession and its aftermath as the Second Great Contraction, where the First Great Contraction was the Great Depression, whereas Hall (2011) calls this period as the Great Slump.

${ }^{2}$ Recently, Bagliano and Morana (2015) investigate the structural determinants of the Great Moderation and the transition to the Great Recession.
} 
Modelling volatility is challenging for econometricians as it is typically an unobserved phenomena, however with some well-known stylized facts. For example, as shown by Fernández-Villaverde and Rubio-Ramírez (2010), time-varying volatility, namely periods of high volatility followed by periods of low volatility, is an important feature of macroeconomic times series. To describe fluctuations in volatility, researchers frequently employ some form of generalized autoregressive conditional heteroskedasticity (GARCH) models developed by Engle (1982) and Bollerslev (1986) under the assumption of a stable variance process. Typically, a high degree of persistence in conditional macroeconomic volatility is found in empirical studies. However, it has been also proved that this persistence if often driven by the neglecting of breaks in the variance (see, e.g., Diebold, 1986) ${ }^{3}$ Indeed, some shocks can cause abrupt breaks in the unconditional variance of returns and are equivalent to structural breaks in the parameters of the GARCH process governing the conditional volatility of returns. Generally those shocks invalidate statistical inference. In such a case, including dummy variables to account for such shifts diminishes the degree of persistence in conditional volatility. For example, using GARCH specifications with breaks in volatility, Fang et al. (2008) and Fang and Miller (2008) show that the time-varying variance falls sharply or disappears, once they incorporate the break in the variance equation of output. Also Balke and Fomby (1991), Atkinson et al.(1997) or Darné and Diebolt (2004), inter alia, show that specific events have a dramatic impact on modelling macroeconomic and financial time series. This type of event includes, for example, oil shocks, wars, financial slumps, changes of policy regimes, natural disasters, etc. Due to their

\footnotetext{
${ }^{3}$ Kim and Nelson (1999), Mills and Wang (2003), Summers (2005), and Smith and Summers (2009) implement a Markov switching heteroskedasticity approach with two states to assess volatility in the growth rate of real GDP. The GARCH modeling approach provides an alternative to deal with this issue by assuming a constant variance process.
} 
unpredictable nature and large impact on macroeconomic and financial relationships, these extraordinary events are referred to as (infrequent) large shocks and are often identified as breaks, jumps or outliers. Finally, as suggested by Hamilton (2008), even if one's interest is in estimating the conditional mean, correctly modeling the conditional variance can still be quite important, for two reasons: (i) hypothesis tests about the mean in a model in which the variance is misspecified will be invalid, with a "spurious regression" possibility; and (ii) the inference about the conditional mean can be inappropriately influenced by outliers and high-variance episodes if one has not incorporated the conditional variance directly into the estimation of the mean, and infinite relative efficiency gains may be possible. $4^{4}$

To the best of our knowledge, only one study examines the presence of breaks in mean and in variance to assess the effects of breaks on macroeconomic volatility measurement, including the Great Recession period. Gadea et al. (2014) focus only on the US and identify breaks in mean that can have only a permanent effect and not a temporary effect. In this paper, we identify permanent and temporary breaks for both mean and variance in the GDP series of 10 advanced countries (US, UK, Japan, Germany,

\footnotetext{
${ }^{4}$ In the strictest sense, the efficiency of an estimator is determined by the ratio of its minimum possible variance to its actual variance. Only when the ratio is equal to one - that is, when it has the lowest possible variance - is an estimate considered efficient. An estimator is asymptotically efficient if it reaches efficiency with large samples. More generally, an estimator is considered to be efficient if its sampling variance is relatively small, resulting in small standard errors. It follows that some estimators are more efficient than others, and thus the concept of relative efficiency is useful for assessing competing estimators (Andersen, 2007). Hamilton (2008) shows that there is a gain in asymptotic efficiency for the estimation of the parameters in the conditional mean when taking into account outliers and high-variance episodes. The relative efficiency gain of estimating by incorporating outliers and high-variance episodes relative to estimating without incorporating these events can become infinite as the sample size grows for typical values of GARCH parameters. See also Harden and Desmarais (2011).
} 
France, Italy, Canada, Australia, Spain and, the Netherlands). Our empirical results do not give evidence to the end of the Great Moderation period but rather that the Great Recession is characterized by a dramatic short-lived effect on the output growth but not on its volatility, at least for all the countries included in the analysis. Therefore, from our analysis based on recent GDP data, there is currently no evidence of a new regime of high macroeconomic volatility. Then, we show that neglecting the breaks in mean and in variance can lead to spurious econometric results as regards (i) macroeconomic volatility modelling, and (ii) relationships between output growth and output volatility. We find that the time-varying variance is well modeled by a $(\mathrm{G}) \mathrm{ARCH}$ process for Canada, France, Italy and Spain, and disappears for Australia, Germany, Japan, the Netherlands, the UK and the US. Finally, we find no relationship between output growth volatility and output growth once we account for breaks, using GARCH-inmean model.

The remainder of this paper is organized as follows: Section 2 briefly describes the methodology of break detection for both GDP growth rates and its variance, and presents the results. The effects of breaks on output volatility modeling are presented in Section 3. Section 4 discussed the growth-volatility relationship. Finally, Section 5 concludes.

\section{Detecting breaks}

In this section, we present the methodology we implement in order to detect breaks within the GDP series, for both mean and variance, as well as the main empirical results we get. We focus on quarterly growth rates of real GDP series stemming from Quartertly National Accounts of each country, as provided by the OECD in its Economic Outlook database. All the series start in 1970Q1 and end in 2015Q4. 


\subsection{Detection of breaks in mean}

Breaks in macroeconomic series reflect extraordinary, infrequently occurring events or shocks that have major effects on modeling macroeconomic time series. There are several methods stemming from the statistical field for detecting breaks or outliers based on the so-called intervention analysis approach, as originally put forward by Box and Tiao (1975). In this paper, we implement an improved detection algorithm proposed by Chen and Liu (1993), which is readily available with slight modifications in TRAMO/SEATS by Gómez and Maravall (1997). Especially, we focus on break detection from AutoRegessive Moving-Average (ARMA) models to emphasize the large shocks that have affected the output growth. Let's assume that we observe $\left(y_{t}\right)$ the quarterly growth rate of macroeconomic output which follows the following process:

$$
y_{t}=z_{t}+f(t)
$$

where

$$
\phi(L) z_{t}=\theta(L) a_{t} \quad a_{t} \sim N\left(0, \sigma_{a}^{2}\right)
$$

where $z_{t}$ is an $\operatorname{ARMA}(p, q)$ process 5 ( $L$ being the usual lag operator), and $f(t)$ contains exogenous disturbances or breaks. Following Chen and Liu (1993), we will consider three various types of breaks: additive outlier (AO), level shift (LS) and temporary change (TC). The specifications for different $f(t)$ are as follows:

$$
\begin{array}{ll}
\text { AO: } & f_{A O}(t)=\omega_{A O} I_{t}\left(\tau_{j}\right) \\
\text { LS: } & f_{L S}(t)=[1 /(1-L)] \omega_{L S} I_{t}\left(\tau_{j}\right) \\
\text { TC: } & f_{T C}(t)=[1 /(1-\delta L)] \omega_{T C} I_{t}\left(\tau_{j}\right)
\end{array}
$$

\footnotetext{
${ }^{5}$ The orders $p$ and $q$ of the ARMA model are based on specification tests and information criteria.
} 
where $\omega_{i}$, for $i=\mathrm{AO}, \mathrm{LS}, \mathrm{TC}$, denotes the magnitude of the break $I_{t}\left(\tau_{j}\right)$ is an indicator function that takes the value of 1 at time $t=\tau_{j}$ and 0 otherwise; $\tau_{j}$ being the unknown date at which the break occurs, with $j=1, \ldots, m$, and $m$ is the number of breaks. These various types of breaks differently affect the observations: AO causes an immediate and one-shot effect on the observed series; LS produces an abrupt and permanent step change in the series (permanent shock); TC produces an initial effect which dies out gradually with time (transitory shock). In this latter case, the parameter $\delta$ controls the pace of the dynamic dampening effect $(0<\delta<1)]^{7}$ Note also that the detection algorithm provides an estimated date for the break through a sequential procedure. We refer to Appendix A for more details on the break detection methodology.

Now we apply this methodology in order to detect outliers on GDP growth rate series for the 10 countries considered in our analysis (US, UK, Japan, Germany, France, Italy, Canada, Australia, Spain, and the Netherlands.), from 1970Q1 to 2015Q4 In Table 1, all detected breaks are given by country, with their type, timing and $t$-statistics. In addition, we also associate the date of each break to a specific event that occurred near that date.

First, we find breaks for all the output growths and many of the detected large negative breaks are associated with the Great Recession. Clearly, all the countries in

\footnotetext{
${ }^{6}$ More precisely, it is considered that AOs are outliers which are related to an exogenous change in the series with no permanent effects, whereas TCs and LSs are more in the nature of structural changes. TCs represent short-lived shifts in a series with a return to previous levels whereas LSs are more the reflection of permanent shocks. In the remainder of the paper, we use the term "break" for AO, TC and LS.

${ }^{7}$ The values of delta cannot be estimated but have to be specified. TRAMO/SEAT chooses in its default option to set delta $=0.7$. We have specified different values for delta (between 0.1 to 0.9 ) and choose the value that minimizes the AIC and BIC criteria. Note that the AO and LS are two boundary cases of a TC, where $\delta=0$ and $\delta=1$, respectively.

${ }^{8}$ Source: OECD, Main Economic Indicators database.
} 
the sample present a break in mean during this recent macroeconomic recession, except Australia, reflecting thus the large synchronization among advanced countries of this specific event, as shown for example by Imbs (2010). This result confirms the findings of Balke and Fomby (1994) and Darné and Diebold (2004) that severe recessions can be associated with outliers.

More specifically, a sequence of breaks appears among countries: Italy being the first country to be affected in 2008Q2, then Spain and the UK in 2008Q3, Canada, France, Japan and the US in 2008Q4, and last Germany and the Netherlands in 2009Q1. When looking at the amplitude of breaks, Japan was strongly hit through a sequence of two consecutive breaks, as an additive outlier is also detected in 2009Q1. Further, Germany and Japan are among the most affected countries, which seems consistent with economic facts. Indeed, the German and Japanese economies possess an exportled growth that was strongly impacted by the collapse in global trade (see Baldwin, 2009).

Another great common feature visible within those results is the type of breaks. Indeed, most of the countries experience a temporary change (TC break) in output growth during the Great Recession period, meaning that the economy was hit by the financial shock but recovers after few quarters, between two or three quarters. In addition, we get that the estimated pace of recovery was quite low in general as $\hat{\lambda}$ is close to 0.6 or 0.7 , except for Italy that recovers at a lower speed $(\hat{\lambda}=0.8)$. Further, the Great Recession had a very short-lived impact (one quarter) on three countries (Germany, Japan, and the Netherlands) as they experienced an additive outlier. In fact, according to those results, it means that there is no definitive reduction of the output growth after the recession; otherwise a level shift break would have been preferred 9 This latter result shed some light on the current economic debate about the possible loss

${ }^{9}$ Gadea et al. $(2014,2015)$ also find that the US GDP growth rate does not have any structural (permanent) change in the mean. 
of potential growth in the wake of the Great Recession and thus does not imply any evidence that underlying growth has been durably affected by the recession, though there may be a drop in the level of output. This latter hypothesis cannot be assessed here by our approach.

In addition to breaks related to the Great Recession, other breaks are detected within some countries, associated with the first and second oil shocks. The UK and the US, oil producers, experienced a positive shock in 1979Q2 and 1978Q2, respectively, and in 1973Q1 (only for the UK), whereas the negative shocks in 1974Q1 and in 1979Q3 for the UK are likely to due to economic recessions at that time. Last, we point out that the dotcom bubble of the nineties, which was largely financed by equity instead of debt, was much less detrimental to economic growth, as only UK and Spain exhibit a short-lived break during this specific period of time. Overall, it turns out that the nature of recession appears to be a strong determinant of the type of break and hence of its macroeconomic impact. A balance sheet crisis, as the last Great Recession was, seems to largely and durably affect the drivers of growth. Finally, the positive shock in 1976Q4 for Australia can be explained by the fact that the inflation in late 1976 is particularly high and that necessitated a change in the monetary policy with the adoption of monetary aggregate targeting.10

Note that some important events are not associated with breaks in the mean, suggesting that these events could have an impact on the GDP growth but not enough large to be considered as an extraordinary event. For example, Euro adoption in 1999Q1 for the European countries, the European Union accession (1973Q1 for the UK; 1986Q1 for Spain), the North American Free Trade Agreement (NAFTA) in

\footnotetext{
${ }^{10}$ For Spain it is more difficult to find an economic event associated with the outliers detected in 1990Q4 and 1991Q1. These outliers seem to be due to statistical procedures at the National Statistical Institute. These outliers do not appear with the National Accounts (base 2000) while they are present in the NA (base 1995).
} 
1994Q1 for Canada and the US, the admission of China to the World Trade Organization (WTO) in 2001Q4, some military conflicts involving some countries of interest (e.g., the Gulf war in 1990-1991, the Bosnian war in 1994-1995, the Iraq war in 20032011) or financial crises (the Asian financial crisis 1997-1998, the European sovereign debt crisis in 2009).

We now look at the effect of taking breaks-in-mean into account on some basic statistics. Table 3 presents summary statistics for the output growth variables of all countries, for both original and break-in-mean-adjusted series. As regards the original variables, empirical statistics indicate that none of those series is Normally distributed. Australia is more volatile, as measured by standard deviation, than other countries. As regards higher moments of the distribution, France, Germany and Japan exhibit evidence of significant negative skewness and all the countries display excess kurtosis. Blanchard and Simon (2001) note that the distribution of output growth exhibits excess kurtosis, if large and infrequent shocks occur. This suggests that the evidence of kurtosis may reflect extreme changes in mean and variance of growth rate, such as the Great Moderation and the Great Recession. The Ljung-Box test leads to the presence of serial correlation in the series, except for Germany and the Netherlands. The Lagrange Multiplier test for the presence of ARCH effects clearly indicates that all output growth variables, except Germany and the UK, show strong conditional heteroscedasticity.

Let's turn now to breaks-in-mean adjusted series, in order to adjust GDP growth series for breaks-in-mean, we incorporate the various types of outliers based on dummy variables that take a value of one from each point of structural break onwards and take a value of zero elsewhere. Once breaks are accounted for, measures of nonNormality in adjusted series improve, sometimes quite dramatically, reducing excess skewness and excess kurtosis. Excess skewness disappears for France and Japan, 
implying that the breaks are principally responsible for the asymmetries, but still remains for Germany, and becomes significant for the US. Excess kurtosis disappears for four countries (Canada, France, Japan and Spain). Therefore, this supports the fact that breaks-in-mean may cause excess kurtosis in time series, as already pointed for example by Carnero et al. (2001). However, it is sticking to note that evidence of conditional heteroscedasticity is still found for all the break-adjusted series, excluding Germany.

From the comparison of basic statistics, it turns out that accounting for breaks diminishes deviation to Normality, which is an expected result. However, this does not prevent from evidence of ARCH effects at this stage.

\subsection{Detection of breaks-in-variance}

Once breaks-in-mean have been identified, we correct the output growth series from those breaks to get breaks-in-mean corrected series $\left(z_{t}\right)$, as defined in equation (1). We first test for breaks-in-variance starting from adjusted series $\left(z_{t}\right)$ using the Bai and Perron $(1998,2003)$ approach $\sqrt[11]{1}$ Following McConnell and Perez-Quiros (2000) and Stock and Watson (2003, 2005), we assume that, for each country, the GDP growth corrected from breaks-in-mean follows a linear autoregressive (AR) process such that: 12

\footnotetext{
${ }^{11}$ Note that Zhou and Perron (2008) show that if there are changes that are not taken into account in the mean of the series, the test suffers from serious size distortions. We have also applied the procedure to detect additive outlier in variance proposed by Franses and Ghijsels (1999) but we did not find outliers.

${ }^{12}$ Peña (1990) and Chen and Liu (1993), among others, show that outliers can bias the estimation of ARMA parameters.
} 


$$
z_{t}=\phi_{0}+\sum_{i=1}^{p} \phi_{i} z_{t-i}+\varepsilon_{t}
$$

where $\varepsilon_{t}$ is the serially uncorrelated error term. The lag order $p$ in the $\operatorname{AR}(p)$ model is selected from the Schwarz Bayesian criterion (SBC), with the maximum lags $p_{\max }=q(T / 100)^{1 / 4}$ where $q=4$ for quarterly data ${ }^{13}$

Once parameters in equation (4) have been estimated, we test for breaks-in-variance in the absolute values of the estimated residuals, $\hat{\varepsilon}_{t}$, from the following equation:

$$
\left|\hat{\varepsilon}_{t}\right|=\alpha+u_{t}
$$

where $u_{t}$ is the regression error term at time $t \cdot 14$

In addition to the Bai-Perron test, we also applied two other well-known breakin-variance detection procedures: the iterative cumulative sum of squares (ICSS) algorithm proposed by Sansó et al. (2004) which is a CUSUM-type test ${ }^{15}$, and the test put forward by Sensier and van Dijk (2004).

The test procedures of Bai-Perron and ICSS are break tests in the unconditional variance, while Sensier-van Dijk use of test for the conditional variance. The estimated

\footnotetext{
${ }^{13}$ To check for remaining residual autocorrelation, we apply the Ljung-Box test for residual serial correlation to each $\operatorname{AR}(p)$ model selected by SBC. If necessary the lag length $p$ is increased until the null of no residual autocorrelation cannot be rejected at the $5 \%$ significance level.

${ }^{14}$ We also used the unbiased estimators of residuals, $\sqrt{\frac{\pi}{2}}\left|\hat{\varepsilon}_{t}\right|$, as suggested by McConnell and PérezQuirós (2000), and found the same number of breaks.

${ }^{15}$ The ICSS procedure has been used by Fang et al. (2008) for the G7 countries and Gadea et al. (2014, 2015) for the US. Gadea et al. $(2014,2015)$ found the same break-in-variance than our results for the US in 1984Q1 using the Bai-Perron approach and the ICSS procedure. Note that Rodrigues and Rubia (2011) show that outliers can generate large size distortions in this test, and suggest to identify the variance changes from the outlier-adjusted data. Further, Inclán and Tiao (1994) advise that "it is advisable to complement the search for variance changes with a procedure for outlier detection".
} 
breaks detected by those procedures are very close for most of the countries, giving some robustness to the empirical results. In order to define our break-in-variance dating, we retain the date that common to at least two testing procedures. We refer to Online Appendix for further details on multiple detection procedures and results for breaks in variance.

Results for breaks in variance are presented in the first column of Table $22^{16}$ We find at least one break in volatility in all countries, except for France and Japan, and two breaks for Spain and the UK. Most of the breaks in volatility are associated with the well documented decline in output growth volatility in the eighties (Canada, Italy, the Netherlands and the US), characterized in the literature as the "Great Moderation" period. Spain and the UK experienced a break in volatility almost ten years later (1993Q3 and 1992Q2, respectively). It is noteworthy that in opposition to the previous results as regards break-in-mean detection, the timing of the decline in volatility is not synchronized, as also pointed out by Cecchetti et al. (2006). This observed pattern suggests that there is no clear common shock underlying those breaks in volatility. However, a different timing for the decline in volatility may be related to different learning of good policies 17

Table 2 also displays the comparison of break dates in volatility of GDP growth stemming from our results with those of Fang et al. (2008), Cecchetti et al. (2006), Stock and Watson (2005), and Summers (2005). Break dates estimated through our approach are very much in line with those found by Cecchetti et al. (2006) ${ }^{18}$ whereas there is

\footnotetext{
${ }^{16}$ We find the same breaks in mean and in variance when the sample size ends in 2007Q4.

${ }^{17} \mathrm{We}$ thank the referee for this comment.

${ }^{18}$ Cecchetti et al. (2006) use the same methodology we applied, namely the Bai and Perron (1998, 2003) test, with a shorter sample size (1970Q2-2003Q4) and without searching breaks-in-mean. We tested for breaks-in-variance on the original series, i.e. without non-adjusted break-in-mean series, and found the same break dates than with the adjusted break-in-mean series, except for the second break for
} 
more divergence with break dates estimated by others studies. Note however that the dates estimated for the US are remarkably consistent among studies. There seems to be also a consensus for Canada, excepting the Stock and Watson (2005) study. Different detection methods and different sample periods can explain those divergences: Summers (2005) uses a Markov-Switching model with high and low GDP volatility regimes for quarterly data covering the period 1966Q1-2002Q4; Stock and Watson (2005) test for changes in the variance of AR(4) innovations using the Quandt likelihood ratio on the period 1960Q1-2002Q4; Cecchetti et al. (2006) search for multiple breaks in GDP growth series based on Bai and Perron $(1998,2003)$ approach from 1970Q1 to 2003Q4; and Fang et al. (2008) use modified iterated cumulative sum of squares algorithm proposed by Sansó et al. (2004) to detect structural change in the variance of output growth on the period 1957Q1-2006Q3. Furthermore, the inclusion within the sample of the Great Recession period can bias the estimation of the break dates if this exceptional period, in terms of amplitude and duration, is not taken into account.

A salient feature of those empirical results lies in the fact that once we account for breaks in mean in GDP time series, then no more breaks in volatility are identified during the Great Recession. This empirical result does not give evidence to the end of the Great Moderation regime, in opposition to the results obtained by Canarella et al. (2010) $\sqrt{19}$ but rather that the Great Recession has a dramatically temporary negative effect on the output growth but not on its volatility. This finding suggests that the Great Moderation with its low volatility of growth is likely to continue in the upcoming years. This result also confirms the findings of Chen (2011) that there is a very the UK. These results give robustness of our findings on breaks-in-variance dates.

${ }^{19}$ Canarella et al. (2010) estimate the end of the Great Moderation in 2007, using Markov regimeswitching models. Note that the authors still carry some reservations about their findings. 
high probability of being in a low-volatility regime since $2009-201020$, and the view of Clark (2009) that "macroeconomic volatility will likely undergo occasional shifts between high and low levels, with low volatility the norm." Clark (2009) attributes most of the rise in macroeconomic variability to larger shocks to oil prices and financial markets, or bad luck. In addition, Clark (2009) finds that the increase in volatility during the Great Recession is concentrated in some sectors of the economy (e.g., goods production, investment, and total inflation) whereas the Great Moderation affected all sectors. Moreover, the low volatility of financial market prices since 2011 after the Global Financial Crisis (Chakrabarti and Sen, 2012; Charles and Darné, 2014) provides complementary evidence that the Great Moderation is still on.

\section{Impact of breaks on output volatility modelling}

In this section, we assess the impact on modeling of not taking breaks into account, for both conditional mean and conditional variance. As argued by Fernández-Villaverde and Rubio-Ramírez (2010), modelling volatility is important to understand the source of aggregate fluctuations, the evolution of the economy, and for policy analysis. Further, it is necessary to have an accurate modeling of volatility to propose structural models with mechanisms that generate it (Fernández-Villaverde and Rubio-Ramírez, 2007, 2010; Justiniano and Primiceri, 2008). In this respect, we estimate an $\operatorname{AR}(p)$ GARCH(1,1) model (Bollerslev, 1986) for the growth rate series on three datasets: (1) raw data; (2) break-in-mean adjusted data; and (3) break-in-mean and breakin-variance adjusted data. Indeed, GARCH-type models have proved useful in the measurement of output volatility in the empirical literature.

\footnotetext{
${ }^{20}$ Chen (2011) employs a Markov regime-switching approach in G7 countries from data ending in 2010Q4.
} 
The conditional mean growth rate is supposed to follow an $\mathrm{AR}(\mathrm{p})$ process of the form:

$$
x_{t}=\phi_{0}+\sum_{i=1}^{p} \phi_{i} x_{t-i}+\varepsilon_{t},
$$

where for all $t, x_{t}=y_{t}$ for raw series or $x_{t}=z_{t}$ for break-in-mean corrected series, with

$$
\begin{aligned}
& \varepsilon_{t}=v_{t} \sqrt{\sigma_{t}^{2}} \\
& \varepsilon_{t} \sim N\left(0, \sqrt{\sigma_{t}^{2}}\right), \quad v_{t} \sim \text { i.i.d.N }(0,1), \\
& \sigma_{t}^{2}=\omega+\alpha \varepsilon_{t}^{2}+\beta \sigma_{t-1}^{2}
\end{aligned}
$$

The lag order $p$ is selected from the Schwarz Bayesian criterion (SBC) in order to capture growth dynamics and to produce uncorrelated residuals. The parameters should satisfy $\omega>0, \alpha \geq 0$ and $\beta \geq 0$ to guarantee the positivity of the conditional variance. The stationarity of the process (the second-order moment condition) is guaranteed by the restriction $\alpha+\beta<1$. Ling and McAleer (2002a, 2002b) derived the regularity conditions of a $\operatorname{GARCH}(1,1)$ model as follows: $E\left[\varepsilon_{t}^{2}\right]=\frac{\omega}{1-\alpha-\beta}<\infty$ if $\alpha+\beta<1$, and $E\left[\varepsilon_{t}^{4}\right]<\infty$ if $k \alpha^{2}+2 \alpha \beta+\beta^{2}<1$, where $k$ is the conditional fourth moment of $z_{t}{ }^{21} \mathrm{Ng}$ and McAleer (2004) underline the importance of checking these conditions.

The sum of $\alpha$ and $\beta$ quantifies the persistence of shocks to conditional variance, meaning that the effect of a volatility shock vanishes over time at an exponential rate. The GARCH models are short-term memory which define explicitly an intertemporal causal dependence based on a past time path. It is possible to shed light on the speed of the mean reversion process from GARCH parameters, based on the half-life concept. Half-life gives the point estimate of half-life $(j)$ in quarters given as $(\alpha+\beta)^{j}=\frac{1}{2}$, so the half-life is given by $j=\ln (0.5) / \ln (\alpha+\beta)$, i.e. it takes for half of the expected reversion back towards $E\left(\sigma^{2}\right)$ to occur (Andersen and Bollerslev, 1997). When $\alpha+\beta=1$

\footnotetext{
${ }^{21}$ Under the assumption of a Normal distribution $k=3$, so the condition becomes $3 \alpha^{2}+2 \alpha \beta+\beta^{2}<1$.
} 
an Integrated GARCH (IGARCH) model is defined (Engle and Bollerslev, 1986), for which the unconditional variance is not finite, implying that the shocks to the conditional variance indefinitely persist.

Table 4 provides the estimation results for the $\operatorname{AR}(p)-\operatorname{GARCH}(1,1)$ models. The parameters of the volatility models are estimated by maximizing the (quasi) loglikelihood function from the quasi-Newton method of Broyden, Fletcher, Goldfarb and Shanno (BFGS) ${ }^{22}$ For each country, the best model is given in bold face, owing to the higher value of the log-likelihood. We comment below the results for each of the three datasets.

\section{Original data $\left(y_{t}\right)$.}

The conditions of stationarity and existence of the fourth moment are satisfied for almost all the countries (except for Canada, Italy, the UK and the US), showing that the effect of a volatility shock vanishes over time at an exponential rate. Japan is modeled by a $\operatorname{GARCH}(1,1)$ process and exhibits a slightly high volatility persistence, with persistence estimate of 0.870 and half-life of shocks to volatility near to five quarters, whereas Australia, France and Germany are modeled by an $\mathrm{ARCH}(1)$ process, suggesting a low level of persistence (less than one quarter). Finally, the IGARCH process captures the temporal pattern of volatility for the Netherlands and Spain, implying that the shocks to the conditional variance persist indefinitely ${ }^{23}$

\section{Break-in-mean-adjusted data $\left(z_{t}\right)$.}

When breaks-in-mean are taken into account, the level of volatility persistence is

\footnotetext{
${ }^{22}$ To estimate the GARCH models, we use the package G@RCH 7.0 for Ox.

${ }^{23}$ An IGARCH model has been estimated because the stationarity condition of the GARCH model were not satisfied.
} 
slightly modified for most of the countries. The value of $\alpha$ decreases and the value of $\beta$ increases when the data are cleaned of breaks for Canada, the Netherlands and Spain, as also found by Carnero et al. (2001). Note that the GARCH model did not satisfy the regularity and/or non-negativity conditions from original data for Canada, the Netherlands, Spain and the UK but these conditions are satisfied from break-in-mean-adjusted data, except for Italy, suggesting that outliers can bias these conditions. This finding confirms that of $\mathrm{Ng}$ and McAleer (2004), showing that outliers can affect the moment conditions of GARCH models. Further, the volatility of output growth for the UK is now modeled by a $\operatorname{GARCH}(1,1)$ with a high degree of persistence, $\alpha+\beta=0.970$. More interesting, the (G)ARCH effect disappears for Australia, Germany and the US when outliers are taken into account, suggesting that a homoscedastic error process is more suitable. Further, the log-likelihood from break-adjusted data is higher than the one from the original data, showing the relevance of taking into account outliers in modeling the output growth, from a goodness-of-fit point of view.

\section{Accounting for break-in-variance in break-in-mean adjusted data $\left(z_{t}\right)$.}

We now consider the break-in-mean adjusted data $\left(z_{t}\right)$ and we estimate the model given by equation (6) and by the following equation for the conditional variance:

$$
\sigma_{t}^{2}=\omega+\alpha \varepsilon_{t}^{2}+\beta \sigma_{t-1}^{2}+\sum_{i=1}^{m} \omega_{i} d_{i t}
$$

where $m$ is the number of detected breaks in the variance, $d_{i t}$ is the dummy variable corresponding to the $i^{\text {th }}$ detected break, and $\omega_{i}$ is the impact measure of $d_{i t}$. We use the dates of break presented in Table 2. The parameter estimates of dummies variables are all found to be significant ${ }^{24}$ The negative estimate of the dummy variable $\left(d_{1}\right)$ in the variance equation reflects exactly the Great Moderation for Canada, Italy, the

\footnotetext{
${ }^{24}$ Note that Fang et al. (2008) find non-significant estimates of some dummy variables in the AR and GARCH models.
} 
Netherlands, Spain $\left(d_{2}\right)$, the UK and the US. For all the countries, the improvement of the value of the maximum log-likelihood (LL) indicates that the $\operatorname{GARCH}(1,1)$ model from break-in-mean-adjusted data with structural breaks in volatility appears to be the most relevant to fit the data, showing the importance to account for breaks, both in mean and in variance, when modeling the output growth.

When structural breaks are incorporated in the GARCH model, the volatility persistence substantially drops for Canada, Italy and Spain, with a level of 0.601, 0.515 and 0.775 , respectively (with a decrease of the persistence of almost $30 \%$ ). It is well known that these shocks can bias the estimated persistence of volatility (see, e.g., Lamoureux and Lastrapes, 1990; Mikosch and Starica, 2004; Hillebrand, 2005). Moreover, the estimated half-life of shocks changes dramatically. For example, the half-life is of nearly four quarters for Canada from the original data whereas it is of one quarter after accounting for structural break in variance. That is, once breaks are accounted for, a shock is expected to have a much lower duration. Further, the estimates of GARCH parameters, $\alpha_{1}$ and $\beta_{1}$, not only fall in size but also become non-significant in the specification that includes the variance dummy variable for Japan, the Netherlands and the UK, indicating no $(\mathrm{G}) \mathrm{ARCH}$ effects. That is, the dummy variable replaces the GARCH effect. Moreover, the GARCH(1,1) model reduces to $\mathrm{ARCH}(1)$ for Italy.

Overall, empirical results presented in this section underline that once we correct for breaks in volatility, then the $\mathrm{ARCH}(1)$ model appropriately captures volatility of GDP growth rate for France and Italy, and a GARCH(1,1) for Canada and Spain, whereas conditional homoscedasticity prevails for Australia, Germany, Japan, the Netherlands, the UK and the US. Thus we can conclude from those results that the GARCH evidence and high persistence property that appear in many research papers dealing with macroeconomic variables mainly reflect the Great Recession and the Great Moderation effects. Once taking breaks into account, this specific variance 
dynamics disappears for some countries.

\section{Revisiting the growth-volatility relationship}

A number of studies examine the issue of how the volatility of the GDP growth rate affects the growth rate of GDP. That is, does decreased GDP growth rate volatility cause a higher or lower GDP growth rate? Alternative theoretical models give mixed results: negative (e.g., Martin and Rogers, 1997, 2000), positive (e.g., Black, 1987; Blackburn, 1999), or independent relationships (Phelps, 1968; Lucas, 1972) between output growth volatility and output growth $\sqrt[25]{5}$ Empirical evidence of the growth-volatility relationship is also mixed (see, e.g., Caporale and McKierman, 1996, 1998; Fountas and Karanasos, 2006) by applying a GARCH-in-mean (GARCH-M) model (Engle et al., 1987). Fang and Miller (2008) and Fang et al. (2008) find no link between volatility and growth by taking into account a structural break in the volatility process.

We re-examine the effect of output volatility on its growth by estimating GARCHM models using the three datasets considered in the previous section. The mean growth rate is defined as:

$$
x_{t}=\phi_{0}+\sum_{i=1}^{p} \phi_{i} x_{t-i}+\lambda \sigma_{t}+\varepsilon_{t}
$$

where for all $t, x_{t}=y_{t}$ for raw series or $x_{t}=z_{t}$ for break-in-mean-adjusted series, where $\sigma_{t}$ equals the standard deviation of the conditional variance $\left(\sigma_{t}^{2}\right)$, and $\lambda$ measures the amplitude of the volatility effect. As in Fang and Miller (2008) and Fang et al. (2008), we introduce lagged output growth into the conditional variance equation in the GARCH-M model to avoid potential endogeneity bias. The variance equation is thus given by

\footnotetext{
${ }^{25}$ See Fang and Miller (2008) for a discussion of the growth-volatility relationship.
} 


$$
\sigma_{t}^{2}=\omega+\alpha \varepsilon_{t-1}^{2}+\beta \sigma_{t-1}^{2}+\theta x_{t-1}
$$

where $\theta$ measures the level effect of the output growth on the variance. Table 5 displays the GARCH-M estimation results for original data and break-in-mean adjusted data. For the original data, we find a significant relationship between output volatility and its growth (estimated by $\lambda$ ) for only two countries from a (I)GARCH(1,1)-M model, with a positive relationship for Canada and a negative relationship for Spain. When breaks-in-mean are taken into account, the growth-volatility relationship disappears for both countries, suggesting that the breaks bias the estimation of this relationship.

Now we incorporate breaks-in-variance in the GARCH-M model through the following equation:

$$
\sigma_{t}^{2}=\omega+\alpha \varepsilon_{t-1}^{2}+\beta \sigma_{t-1}^{2}+\theta x_{t-1}+\sum_{i=1}^{m} \omega_{i} d_{i t}
$$

where $m$ is the number of detected breaks in the variance, $d_{i t}$ is the dummy variable corresponding to the $i^{t h}$ detected break, and $\omega_{i}$ is the impact measure of $d_{i t}$. When breaks in volatility are incorporated in the estimation on the GARCH-M model, we find no relationship between output volatility and its growth, whatever the country ${ }^{26}$ This result confirm those obtained by Fang and Miller (2008) and Fang et al. (2008). From a macroeconomic point of view, this implies that economic performances, as measured by GDP growth, do not depend on the uncertainty as measured by GDP volatility.

\footnotetext{
${ }^{26}$ Note that the effect of the lagged growth rate of output on its conditional variance $(\theta)$ has been found non-significant for all the countries.
} 


\section{Conclusion}

In this paper, we focused on break detection in mean and in variance on output growth for a set of advanced countries, based on statistical test procedures. It turns out that the Great Recession period is characterized by large breaks in mean of transitory nature, while dates of breaks in variance are consistent with the Great Moderation period in the eighties. This leads us to conclude that there is no evidence favoriting an end of the low output volatility period, but rather that the Great Recession has a dramatically short-lived effect on the output growth but not on its volatility.

In addition, we showed that neglecting the breaks both in mean and in variance can have large effects on output volatility modeling based on GARCH specifications. We find that the time-varying variance is well modeled by a $(\mathrm{G}) \mathrm{ARCH}$ process for Canada, France, Italy and Spain, and disappears for Australia, Germany, Japan, the Netherlands, the UK and the US. Finally, we find no relationship between output growth volatility and output growth once we account for breaks, using GARCH-in-mean model. 


\section{References}

[1] Ahmed, S., Levin, A., Wilson, B.A. (2004). Recent U.S. macroeconomic stability: Good policies, good practices, or good luck? The Review of Economics and Statistics, 86, 824-32.

[2] Andersen, R. (2007). Modern Methods for Robust Regression. Quantitative Applications in the Social Sciences. Sage: London.

[3] Andersen, T., Bollerslev, T. (1997). Intraday periodicity and volatility persistence in financial markets. Journal of Empirical Finance, 4, 115-158.

[4] Atkinson, A.C., Koopman, S.J., Shephard, N. (1997). Detecting shocks: Outliers and breaks in time series. Journal of Econometrics, 80, 387-422.

[5] Bagliano, F.C., Morana, C. (2015). It ain't over till it's over: A global perspective on the Great Moderation-Great Recession interconnection. Working paper No 424, Collegio Carlo Alberto.

[6] Bai, J., Perron, P. (1998). Estimating and testing linear model with multiple structural changes. Econometrica, 66, 47-78.

[7] Bai, J., Perron, P. (2003). Computation and analysis of multiple structural change models. Journal of Applied Econometrics, 18, 1-22.

[8] Baldwin, R. (2009). The Great Trade Collapse: Causes, Consequences and Prospects. VoxEU eBook, Centre for Economic Policy Research.

[9] Balke, N., Fomby, T.B. (1991). Shifting trends, segmented trends, and infrequent permanent shocks. Journal of Monetary Economics, 28, 61-85. 
[10] Balke, N., Fomby, T.B. (1994). Large shocks, small shocks, and economic fluctuations: Outliers in macroeconomic time series. Journal of Applied Econometrics, 9, 181-200.

[11] Bean, C. (2010). Joseph Schumpeter Lecture The Great Moderation, The Great Panic, and The Great Contraction. Journal of the European Economic Association, 8, 289-325.

[12] Bernanke, B.S. (2004). The Great Moderation. Lecture at Eastern Ectmomic Association, Washington.

[13] Blanchard, O., Simon, J. (2001). The long and large decline in US output volatility. Brooking Papers on Economic Activity, 1, 135-174.

[14] Black, F. (1987). Business Cycles and Equilibrium. New York: Basil Blackwell.

[15] Blackburn, K. (1999). Can stabilization policy reduce long-run growth? Economic Journal, 109, 67-77.

[16] Boivin, J., Giannoni, M. (2006). Has monetary policy become more effective? The Review of Economics and Statistics, 88, 445-62.

[17] Bollerslev, T. (1986). Generalized autoregressive conditional heteroskedasticity. Journal of Econometrics, 31, 307-327.

[18] Box, G.E.P., Tiao, G.C. (1975). Intervention analysis with applications to economic and environmental problems. Journal of the American Statistical Association, 70, 70-79.

[19] Canarella, G., Fang, W., Miller, S.M., Pollard, S.K. (2010). Is the Great Moderation ending? UK and US evidence. Modern Economy 1, 17-42. 
[20] Caporale, T., McKiernan, B. (1996). The relationship between output variability and growth: Evidence from post war U.K. data. Scottish Journal of Political Economy, 43, 229-36.

[21] Caporale, T., McKiernan, B. (1998). The Fischer black hypothesis: Some timeseries evidence. Southern Economic Journal, 63, 765-71.

[22] Carnero, M.A., Peña, D., Ruiz, E. (2001). Outliers and conditional autoregressive heteroskedasticity in time series. Revista Estadistica, 53, 143-213.

[23] Carnero, M.A., Peña, D., Ruiz, E. (2006). Effects of outliers on the identification and estimation of the GARCH models. Journal of Time Series Analysis, 28, 471497.

[24] Cecchetti, S.G., Flores-Lagunes, A., Krause, S. (2006). Assessing the sources of changes in the volatility of real growth. Working paper No 11946, NBER.

[25] Chakrabarti, G., Sen, C. (2012). Stock market cycles and volatility regime switch. In Chakrabarti, G., Sen, C. (eds), Anatomy of Global Stock Market Crashes, Springer.

[26] Charles, A., Darné, O. (2014). Large shocks in the volatility of the Dow Jones Industrial Average index: 1928Û́2013. Journal of Banking \& Finance, 43, 188199.

[27] Chen, C., Liu, L. (1993). Joint estimation of model parameters and outlier effects in time series. Journal of the American Statistical Association, 88, 284-297.

[28] Chen, W. (2011). On the continuation of the Great Moderation: New evidence from G7 countries. SFB 649 Discussion Paper No 2011-060, Humboldt University. 
[29] Clarida, R., Gali, J., Gertler, M. (2000). Monetary policy rules and macroeconomic stability: Evidence and some theory. The Quarterly Journal of Economics, $115,147-80$.

[30] Clark, T.E. (2009). Is the great moderation over? Federal Reserve Bank of Kansas City Economic Review (Fourth Quarter), 5-39.

[31] Darné , O., Diebolt, C. (2004). Unit roots and infrequent large shocks: New international evidence on output. Journal of Monetary Economics, 51, 14491465.

[32] Diebold, F.X. (1986). Modeling the persistence of conditional variances: A comment. Econometric Reviews, 5, 51-56.

[33] Dynan, K., Elmendorf, D., Sichel, D. (2005). Can financial innovation help to explain the reduced volatility of economic activity? FEDs Working Paper No. 2005-54.

[34] Engle, R.F. (1982). Autoregressive conditional heteroskedasticity with estimates of the variance of United Kingdom inflation. Econometrica, 50, 987-1007.

[35] Engle, R.F., Bollerslev, T. (1986). Modelling the persistence of conditional variances. Econometric Reviews, 5, 1-50.

[36] Fang, W., Miller, S.M. (2008). The great moderation and the relationship between output growth and its volatility. Southern Economic Journal, 74, 819-38.

[37] Fang, W., Miller, S.M. (2009). Modeling the volatility of real GDP growth: The case of Japan revisited. Japan and the World Economy, 21, 312-324.

[38] Fang, W., Miller, S.M., Lee, C.S. (2008). Cross-country evidence on output growth volatility: Nonstationary variance and GARCH models. Scottish Journal of Political Economy, 55, 509-541. 
[39] Fernández-Villaverde, J., Rubio-Ramírez, J. (2010). Macroeconomics and volatility: Data, models, and estimation. Working Paper No 16618, NBER.

[40] Ferrara, L., Marcellino, M., Mogliani, M. (2015). Macroeconomic forecasting during the Great Recession: The return of non-linearity? International Journal of Forecasting, 31, 664-679.

[41] Fountas, S., Karanasos, M. (2006). The relationship between economic growth and real uncertainty in the G3. Economic Modelling, 23, 638-47.

[42] Gadea, M.D., Gómez-Loscos, A., Pérez-Quirós, G. (2014). The two greatest. Great Recession vs Great Moderation. Discussion Paper No 1423. Bank of Spain.

[43] Gadea, M.D., Gómez-Loscos, A., Pérez-Quirós, G. (2015). The Great Moderation in historical perspective. Is it that great. Discussion Paper No 1527. Bank of Spain.

[44] Galí, J., Gambetti, L. (2009). On the sources of the great moderation. American Economic Journal: Macroeconomics, 1, 26-57.

[45] Gómez, V., Maravall, A. (1997). Programs TRAMO and SEATS: Instructions for the user (Beta version: June 1997). Working paper No 97001, Ministerio de Economía y Hacienda, Dirección General de Análisis y Programación Presupuestaria.

[46] Hall, R., (2011). The long slump. American Economic Review, 101, 431-469.

[47] Hamilton, J. (2008). Macroeconomics and ARCH. Working Paper No 14151, NBER.

[48] Hansen, B. (1997). Approximate asymptotic p-values for structural change tests. Journal of Business \& Economic Statistics, 15, 60-67. 
[49] Harden, J.J., Desmarais, B.A. (2011). Linear models with outliers: Choosing between conditional-mean and conditional-median methods. State Politics \& Policy Quarterly, 11, 371-389.

[50] Herrera, A.M., Pesavento, E. (2005). The decline in U.S. output volatility: Structural changes and inventory investment. Journal of Business \& Economic Statistics, 23, 462-472.

[51] Hillebrand, E. (2005). Neglecting parameter changes in GARCH models. Journal of Econometrics, 129, 121-138.

[52] Inclan, C., Tiao, G.C. (1994). Use of cumulative sums of squares for retrospective detection of changes of variance. Journal of the American Statistical Association, 89, 913-923.

[53] Imbs, J. (2010). The First Global Recession in Decades. IMF Economic Review, 58, 2, 327-354, December.

[54] Justiniano, A., Primiceri, G.E. (2008). The time varying volatility of macroeconomic fluctuations. American Economic Review 98, 604-641.

[55] Kahn, J., McConnell, M., Perez-Quiros, G. (2002). On the causes of the increased stability of the US economy. Federal Reserve Bank of New York Economic Policy Review, 8, 183-202.

[56] Kim, C., Nelson, C. (1999). Has the US economy become more stable? A Bayesian approach based on a Markov-switching model of the business cycle. The Review of Economics and Statistics, 81, 608-616.

[57] Lamoureux, C.G., Lastrapes, W.D. (1990). Persistence in variance, structural change and the GARCH model. Journal of Business \& Economic Statistics, 8, 225-234. 
[58] McConnell, M., Perez-Quiros, G. (2000). Output fluctuations in the United States: what has changed since the early 1980's? American Economic Review, 90, 1464-1476.

[59] Mikosch, T., Stãricã, C. (2004). Nonstationarities in financial time series, the long-range dependence, and the IGARCH effects. The Review of Economics and Statistics, 86, 378-390.

[60] Mills, T., Wang, P. (2003). Have output growth rates stabilised? Evidence from the G-7 economies. Scottish Journal of Political Economy, 50, 232-246.

[61] Newey, W., West, K. (1987). A simple positive semi-definite, heteroskedasticity and autocorrelation consistent covariance matrix. Econometrica, 55, 703-708.

[62] Newey, W., West, K. (1994). Automatic lag selection in covariance matrix estimation. Review of Economic Studies, 61, 631-653.

[63] Ng, H.G., McAleer, M. (2004). Recursive modelling of symmetric and asymmetric volatility in the presence of extreme observations. International Journal of Forecasting, 20, 115-129.

[64] Ng, S., and Wright, J. H. (2013). Facts and challenges from the Great Recession for forecasting and macroeconomic modeling. Working Papers No 19469, NBER.

[65] Peña, D. (1990). Influential observations in time series. Journal of Business \& Economic Statistics, 8, 235-241.

[66] Reifschneider, D., W. Wascher and D. Wilcox (2013). Aggregate supply in the United States: Recent developments and implications for the conduct of monetary policy, paper presented at the 14th Jacques Polak Annual Conference at the IMF, November 2013. 
[67] Reinhart, C., Rogoff, K. (2009). This Time is Different: Eight Centuries of Financial Folly. Princeton University Press.

[68] Rodrigues, P.M.M., Rubia, A. (2011). The effects of additive outliers and measurement errors when testing for structural breaks in variance. Oxford Bulletin of Economics and Statistics, 73, 449-468.

[69] Sansó, A., Aragó, V., Carrion-i-Silvestre, J. (2004). Testing for changes in the unconditional variance of financial time series. Revista de Economía Financiera, $4,32-53$.

[70] Sensier, M. and D. van Dijk (2004). Testing for volatility changes in U.S. macroeconomic time series. The Review of Economics and Statistics, 86, 3, 833839.

[71] Stock, J., Watson, M. (2003). Has the business cycle changed? Evidence and explanation. The Federal Reserve Bank of Kansas City Economic Symposium Conference Proceedings, Kansas City, 9-56.

[72] Stock, J., Watson, M. (2005). Understanding changes in international business cycle dynamics. Journal of the European Economic Association, 3, 968-1006.

[73] Stock, J., Watson, M. (2012). Disentangling the channels of the 2007-2009 Recession. Working Papers No 18094, NBER.

[74] Smith, P.A., Summers, P.M. (2009). Regime switches in GDP growth and volatility: Some international evidence and implications for modeling business cycles. The B.E. Journal of Macroeconomics, 9.

[75] Summers, P.M. (2005). What caused the Great Moderation? Some cross-country evidence. Economic Review (Third Quarter), Federal Reserve Bank of Kansas City, 5-32. 
[76] Taylor, J.B. (2010). Macroeconomic lessons from the Great Deviation. In NBER Macroeconomics Annual 2010, Vol. 25, 387Ü395, NBER.

[77] Zhou, J., and Perron, P. (2008). Testing for breaks in coefficients and error variance: Simulations and applications. Working Papers No 2008-010, Department of Economics, Boston University. 
Table 1: Large shocks detected in the GDP growth.

\begin{tabular}{|c|c|c|c|c|c|c|}
\hline Country & Date & Type & $\delta^{a}$ & size & t-stat & Events \\
\hline Australia & 1976Q1 & $\mathrm{AO}$ & & 0.036 & 3.90 & Change in monetary policy regime \\
\hline Canada & 2008Q4 & $\mathrm{TC}$ & 0.7 & -0.021 & -3.84 & Great Recession \\
\hline \multirow[t]{2}{*}{ France } & 1974Q4 & $\mathrm{AO}$ & & -0.019 & -4.46 & Oil shock \\
\hline & 2008Q4 & $\mathrm{TC}$ & 0.7 & -0.019 & -4.94 & Great Recession \\
\hline Germany & 2009Q1 & $\mathrm{AO}$ & & -0.048 & -5.58 & Great Recession \\
\hline Italy & 2008Q2 & $\mathrm{TC}$ & 0.8 & -0.023 & -3.71 & Great Recession \\
\hline \multirow[t]{3}{*}{ Japan } & 1974Q1 & $\mathrm{AO}$ & & -0.047 & -4.99 & Oil shock \\
\hline & 2008Q4 & $\mathrm{AO}$ & & -0.036 & -3.78 & Great Recession \\
\hline & 2009Q1 & $\mathrm{AO}$ & & -0.044 & -4.64 & Great Recession \\
\hline \multirow[t]{3}{*}{ Netherlands } & 1979Q1 & $\mathrm{AO}$ & & -0.055 & -5.57 & Oil shock \\
\hline & 1979Q2 & $\mathrm{AO}$ & & 0.052 & 5.35 & Oil shock \\
\hline & 2009Q1 & $\mathrm{AO}$ & & -0.039 & -4.00 & Great Recession \\
\hline \multirow[t]{3}{*}{ Spain } & 1990Q4 & $\mathrm{AO}$ & & 0.036 & 7.38 & \\
\hline & 1991Q1 & $\mathrm{AO}$ & & -0.027 & -5.57 & \\
\hline & 2008Q3 & $\mathrm{TC}$ & 0.7 & -0.020 & -4.67 & Great Recession \\
\hline \multirow[t]{6}{*}{ UK } & 1973Q1 & $\mathrm{AO}$ & & 0.042 & 6.95 & Oil shock \\
\hline & 1974Q1 & $\mathrm{AO}$ & & -0.034 & -5.68 & Oil shock \\
\hline & 1979Q2 & $\mathrm{AO}$ & & 0.038 & 6.30 & Oil shock \\
\hline & 1979Q3 & $\mathrm{TC}$ & 0.7 & -0.034 & -6.51 & Oil shock \\
\hline & 1990Q3 & $\mathrm{TC}$ & 0.7 & -0.021 & -4.15 & Recession \\
\hline & 2008Q3 & $\mathrm{TC}$ & 0.6 & -0.029 & -6.06 & Great Recession \\
\hline \multirow[t]{2}{*}{ US } & 1978Q2 & $\mathrm{AO}$ & & 0.032 & 5.17 & Oil shock \\
\hline & 2008Q4 & $\mathrm{TC}$ & 0.7 & -0.025 & -4.99 & Great Recession \\
\hline
\end{tabular}

Notes: ${ }^{a} \delta$ denotes the parameter which designed to model the pace of the dynamic dampening effect for the outlier TC $(0<\delta<1)$. 
Table 2: Comparison of structural breaks in volatility of GDP growth.

\begin{tabular}{|c|c|c|c|c|c|}
\hline \multirow[b]{2}{*}{ Country } & \multicolumn{5}{|c|}{ Break date } \\
\hline & Our results & $\begin{array}{l}\text { Fang et al. } \\
\qquad(2008)\end{array}$ & $\begin{array}{l}\text { Cecchetti et al. } \\
\text { (2006) }\end{array}$ & $\begin{array}{c}\text { Stock and Watson } \\
\qquad(2005)\end{array}$ & $\begin{array}{c}\text { Summers } \\
(2005)\end{array}$ \\
\hline Australia & $1985 Q 2$ & - & 1984Q3 & - & 1984Q3 \\
\hline Canada & $1987 Q 1$ & 1987Q1 & 1987Q2 & 1991Q2 & 1988Q1 \\
\hline France & - & - & - & 1968Q1 & 1976Q3 \\
\hline Germany & - & - & - & - & - \\
\hline Italy & $1984 Q 1$ & 1996Q1 & 1983Q3 & 1980Q1 & 1980Q2 \\
\hline Japan & - & 1975Q1 & - & - & 1975Q2 \\
\hline Netherlands & $1986 Q 4$ & - & 1983Q4 & - & - \\
\hline & - & - & 1994Q3 & - & - \\
\hline Spain & $1986 Q 1$ & - & 1985Q2 & - & - \\
\hline & $1993 Q 3$ & - & 1993Q2 & - & - \\
\hline UK & $1977 Q 2$ & - & 1981Q2 & 1980Q1 & 1982Q2 \\
\hline & $1992 Q 2$ & 1991Q1 & 1991Q4 & - & - \\
\hline US & $1984 Q 1$ & 1983Q2 & 1984Q2 & 1983Q2 & 1984Q4 \\
\hline Sample & 1970Q2 & 1957Q1 & 1970Q2 & 1960Q1 & 1966Q1 \\
\hline size & 2015Q4 & 2006Q3 & 2003Q4 & 2002Q4 & 2002Q4 \\
\hline Methodology & & CUSUM-type & Bai-Perron & Quandt & Markov-switching \\
\hline & & test & test & LR & model \\
\hline
\end{tabular}


Table 3: Descriptive Statistics and tests.

\begin{tabular}{|c|c|c|c|c|c|c|c|c|}
\hline Country & Outlier & Mean $(\%)$ & St. dev. $(\%)$ & Skewness & Excess Kurtosis & JB & $Q(10)$ & $L M(10)$ \\
\hline \multirow[t]{2}{*}{ Australia } & Original & 0.77 & 0.94 & 0.223 & $1.56^{*}$ & $20.0^{*}$ & $26.4^{*}$ & $32.7^{*}$ \\
\hline & Break-adj. & 0.75 & 0.90 & -0.038 & $0.96^{*}$ & $7.0^{*}$ & 14.4 & $19.8^{*}$ \\
\hline \multirow[t]{2}{*}{ Canada } & Original & 0.68 & 0.82 & -0.132 & $1.17^{*}$ & $11.0^{*}$ & $44.6^{*}$ & $38.1^{*}$ \\
\hline & Break-adj. & 0.62 & 0.73 & -0.244 & 0.31 & 2.5 & $36.7^{*}$ & $45.3^{*}$ \\
\hline \multirow[t]{2}{*}{ France } & Original & 0.53 & 0.56 & $-0.521^{*}$ & $2.03^{*}$ & $39.7^{*}$ & $110.3^{*}$ & $23.3^{*}$ \\
\hline & Break-adj. & 0.58 & 0.50 & 0.211 & 0.09 & 1.4 & $111.1^{*}$ & $20.8^{*}$ \\
\hline \multirow[t]{2}{*}{ Germany } & Original & 0.51 & 0.99 & $-0.519^{*}$ & $3.9^{*}$ & $121.4^{*}$ & 14.1 & 9.0 \\
\hline & Break-adj. & 0.54 & 0.92 & $0.154^{*}$ & $1.4^{*}$ & $15.5^{*}$ & 9.97 & 6.2 \\
\hline \multirow[t]{2}{*}{ Italy } & Original & 0.43 & 0.87 & -0.079 & $1.83^{*}$ & $25.7^{*}$ & $61.9^{*}$ & $26.8^{*}$ \\
\hline & Break-adj. & 0.47 & 0.83 & 0.209 & $1.21^{*}$ & $12.5^{*}$ & $59.7^{*}$ & $64.8^{*}$ \\
\hline \multirow[t]{2}{*}{ Japan } & Original & 0.63 & 1.15 & $-0.649^{*}$ & $2.11^{*}$ & $46.9^{*}$ & $41.7^{*}$ & $18.4^{*}$ \\
\hline & Break-adj. & 0.69 & 1.01 & 0.088 & 0.10 & 0.38 & $50.3^{*}$ & $17.1^{* *}$ \\
\hline \multirow[t]{2}{*}{ Netherlands } & Original & 0.58 & 1.15 & -0.134 & $5.32^{*}$ & $216.2^{*}$ & 11.0 & $30.7^{*}$ \\
\hline & Break-adj. & 0.60 & 0.97 & 0.160 & $2.01^{*}$ & $31.5^{*}$ & 6.1 & $37.3^{*}$ \\
\hline \multirow[t]{2}{*}{ Spain } & Original & 0.63 & 0.80 & -0.019 & $1.28^{*}$ & $12.4^{*}$ & $133.4^{*}$ & $48.5^{*}$ \\
\hline & Break-adj. & 0.66 & 0.70 & -0.068 & 0.21 & 0.48 & $141.9^{*}$ & $29.7^{*}$ \\
\hline \multirow[t]{2}{*}{ UK } & Original & 0.57 & 0.94 & 0.185 & $4.63^{*}$ & $164.2^{*}$ & $20.5^{*}$ & 15.6 \\
\hline & Break-adj. & 0.71 & 0.61 & 0.194 & $0.97^{*}$ & $8.3^{*}$ & $17.7^{* *}$ & $32.3^{*}$ \\
\hline \multirow[t]{2}{*}{ US } & Original & 0.69 & 0.82 & -0.272 & $2.09^{*}$ & $35.5^{*}$ & $39.2^{*}$ & $17.0^{* *}$ \\
\hline & Break-adj. & 0.72 & 0.75 & $-0.474^{*}$ & $1.32^{*}$ & $20.1^{*}$ & $36.8^{*}$ & $29.7^{*}$ \\
\hline
\end{tabular}

Notes: ${ }^{*}$ and ${ }^{* *}$ mean significant at $5 \%$ and $10 \%$ level, respectively. $Q(10)$ is the Box Pierce statistics at lag 10 of the standardized residuals. It is asymptotically distributed as $\chi^{2}(k)$, where $k$ is the lag length. $L M(10)$ is the ARCH LM test at lag 10 . It is distributed as $\chi^{2}(q)$, where $q$ is the lag length. 


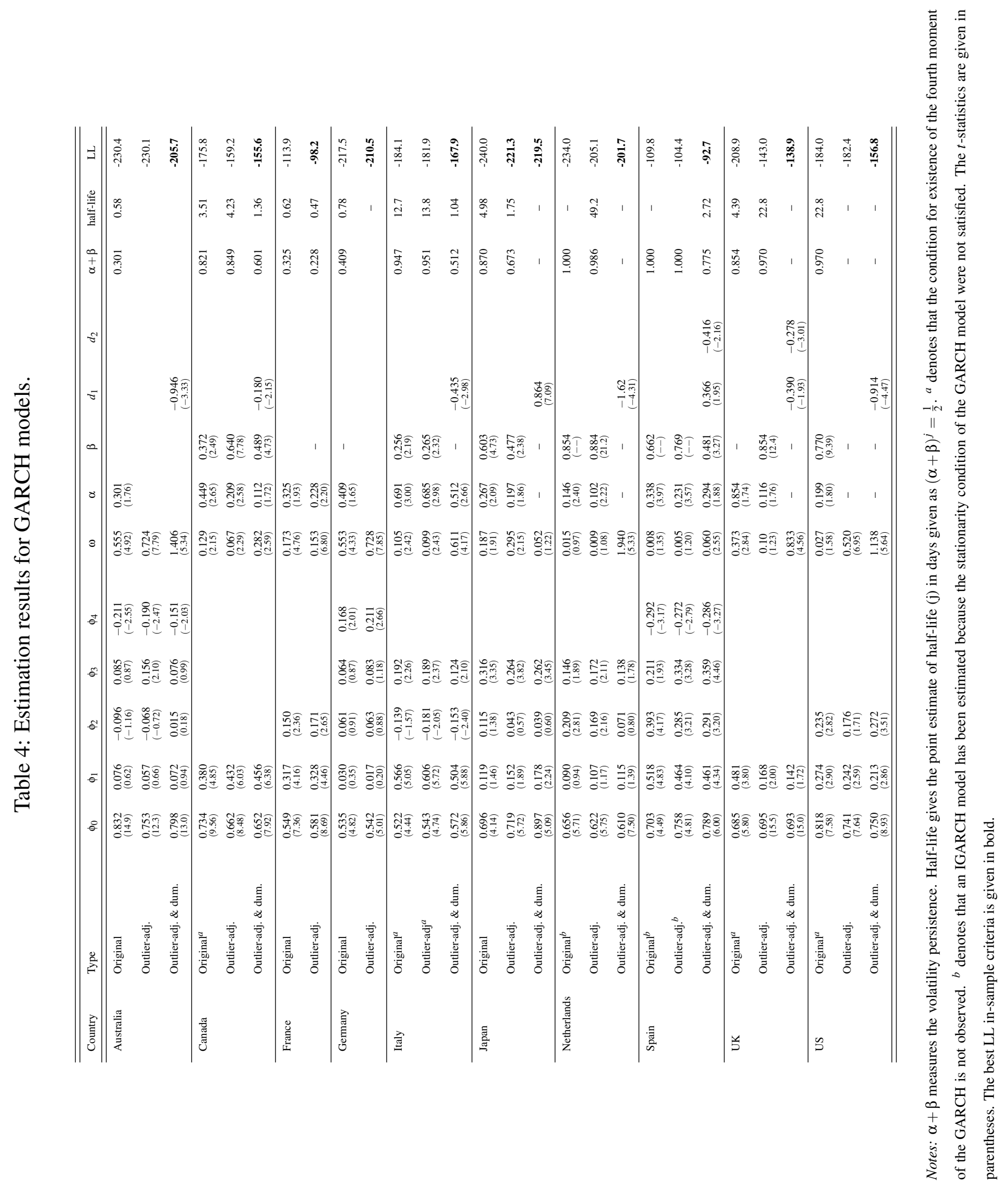




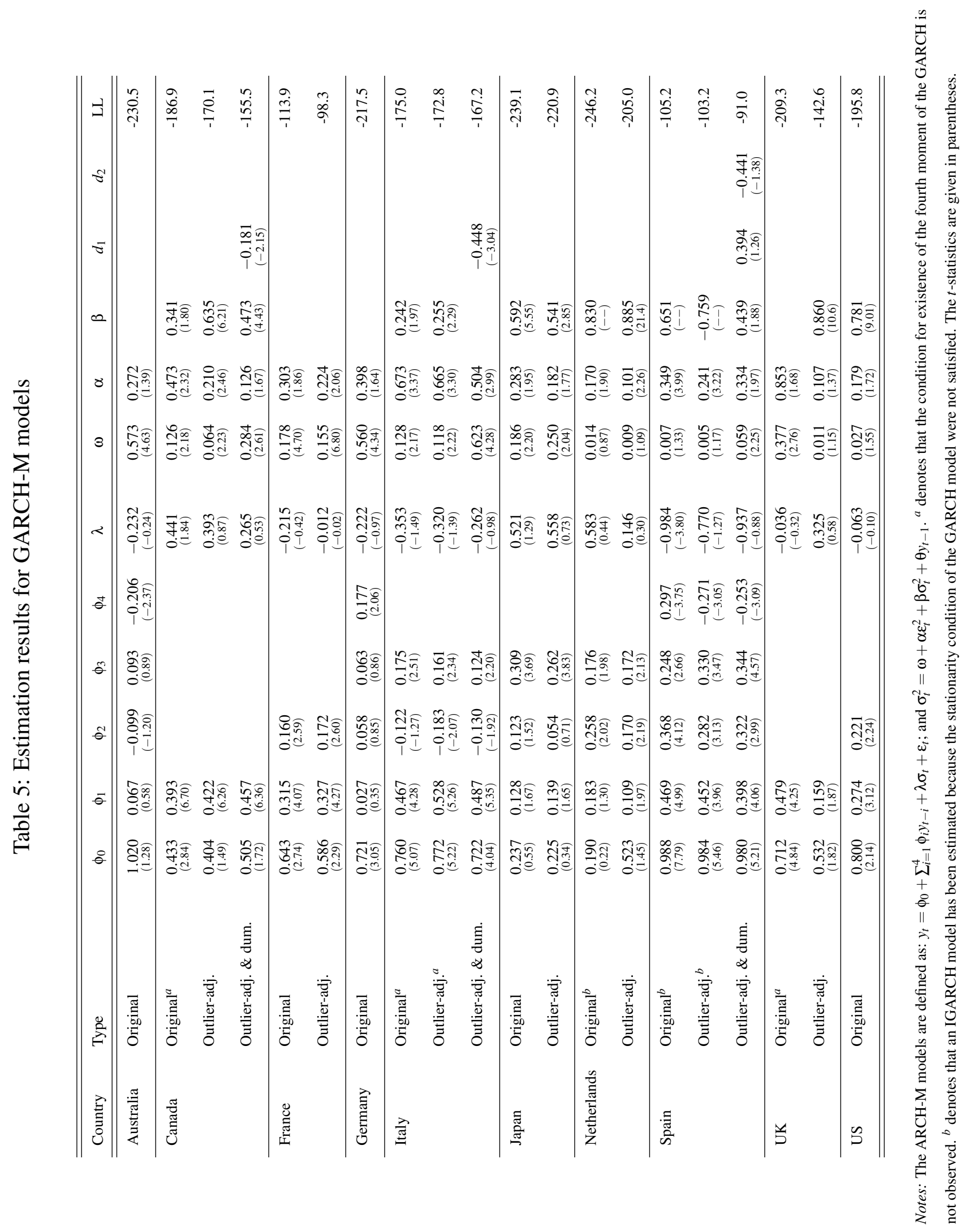

